\title{
Granuloma por cuerpos extraños
}

\section{RAFAEL HUNDA C. y CARLOS R. SILVA MOICA}

Tiene por objeto la presentación de esta historia clinica señaiar la ocurrencia del egranuloma por cuerpo extraño en Clínica Obstétrica. Igualmente es interesante esle caso por la coexistencia en la misma paciente de las más diversas entidades: albuminuria gravídica, preeclampsia, placenta inferior lateral, presentación de pelvis, procidencia del cordón umbilical, granuloma intraperitoneal, anexitis $y$ apendicitis, además de anemia y de un absceso en la región glútea.

Paciente M. L. D. afiliada al ICSS. de 23 años; antecedentes generales $y$ ginecológicos: sin importancia; antecedentes obstétricos: un aborto $\gamma$ un parto espontáneo de término, con tromboflebitis bilateral de los miembros interiores en el puerperio. Desde el 10 de marzo se le encuentran ligeros edomas en los miembros inferiores por 10 cual se le indica dieic declorurada.

Abril 17/53. Se restringe albúminas y líquidos por persistencia de los edomas. Hay ligera hipertensión: 140/90. Serología, negativa; albuminuria, negativa.

Mayo 4/53. Edemas, albuminuria de $3,96 \%$; cilindros granulosos $t$ : heties: $++;$ bacterias: $t+$; plocitos por cam po: +++ . Hipertensión: 160/100. AlAura uterina 28 centimetros. Feto vivo de 8 meses. Se hospitaliza en la Clinica Primero de Mayo y so somete al tratamiento médico de rutina para eslos casos. El laboratorio indica normalidad para NPN, glicemia y uricemia. Dos dias después la tensión arterial es normal.

Mayo 7/53. Nuevo ascenso de TA a 155/100. Epigastraigia. Albuminuria de 5,20 gramos. Se indica ademáa, sodación profunda con fenobarbital.

Mayo 8/53. TA: $140 / 100$, y por la noche 120/80. Persiste la epigastralgia. Albuminuria de 2.15 gramos sin cilindros.

Mayo 9/53. TA: 120/80. Buen estado general. Por la noche inicia peque ña hemorragia genital con discretos dolores de contracción uterina. TV: cuello largo $y$ cerrado.

Mayo 10/53. Desaparece la hemorragia. Persiste la albuminuria 33,45 gr.: y aparece fiebre de 37,8 grados. Se prescribe penicilina.

Mayo 11/53. Continua el estado tobril.

Mayo 12/53. Aparece hemorragia genital con coágulos uterinos. Se hace TV y se diagnostica placenta pre via lateral en multigestante III de $B$ meses; teto vivo, en presentación de pelvis SI alta. Más tarde, con dilatación cervical de 4 centímetros, se prac. tica ruptura artificial de las membranas, pero se produce una procidencia del cordón umbilical por to cual $s e$ 
furede sin dilación ninguna a resolver el caso por cesárea abdominal. Durante la disociación arciforme del segmento se encuentra la placenta allí incertada; se desgarran sus tejidos $y$ a traves de ella se hace extracción podáica del feto, quien respira espontá neamente.

Ia primera semana del post-operatorio transcurre con fiebre continua de pequeñas oscilaciones: 37.5 y 38 grados con un sólo día de 39 grados. Pulso acorde con la temperatura. Estado anémico aparente. Se prescriben antibióticos y suero dextrosado.

Mayo 20/53. Además del estado fobril aparece una tumefacción muy dolorosa en la fosa iliaca derecha que corresponde por TV a una anexitis derecha incipiente. Se decide continuar el tratamiento médico. El cuadro hemático indica anemia hipocrónica y leucocitosis con polinucleosis neutrófila.

Mayo 23/53. En vista de que la paclente continúa agravándose a pesar del tratamiento médico, pues la anemia es más notoria, la sensibilidad en la fosa ilíaca derecha es más marcada $\sin$ que hublere delensa muscular, y la tumelacción en referencia es más grande y dolorosa se solicita el concepto de una junta médica. Dicha junta, doctor Cubillos y uno de nosotros (CRS), no llega a un diagnóstico exacto $y$ preciso pero tenlendo en cuenta la agravación progresiva de la pacien= to y la posibilidad de varias contingencias (apendicitis, anexitis, plastrón epiplóico, compresa inclusive), resuelve de inmediato una laparotomía de precisión. Abierta la cavidad peritoneal. se encuentra gran cantidad de adho- rencias en el flanco y fosa ilíaca derechas $y$ exudado sero-purulento fétido. Matriz subinvolucionada. Liberadas las adherencias se aprecia: inflamación apendicular y signos de peritiflitis: inflamación de la trompa uterina derecha; inflamación, congestión y plastrón del gran epiplón, que se encuentra bloqueando el apéndice y la trompa junto con unas masas carnosas cuyas características se describen adelante.

Se hace en seguida apendicectomía. salpingectomía derecha, extracción del plastrón y de las mencionadas formaciones. La paciente, anestesiada con Ciclo-02, recibió transtusión de sangre y plasma durante la intervención y salió en buenas condiciones de la Sa. la de Cirugía.

Al segundo día del post-operatorio se aomprueba un pequeño absceso glúteo por infección de una inyección. Se drena y se extraen 50 c. c. de pus. En la primera semana la fiebre es intermiterite con pequeñas alzas (37\%. $\left.38^{\circ}\right)$, pero luego se normaliza. Se hace el tratamiento de rigor en estos post-operatorios y se combate la anemia con dos pequeñas transfusiones de 150 c. c. de sangre.

La herida quirúrgica cicatriza normalmente. Sale la paciente de la clínica el 9 de junio de 1953, en condiciones satisfactorias. Persiste albuminuria de 0,33 gr.

El examen anatomopatológico da estos resultados. Examen macroscópico: Apéndice $y$ trompa congestionados $y$ despulidos: Vienen tamblén unas porciones de tejido, de aspecto adiposo de color rojo oscuro. La más grande tiene $9 \times 7 \times 2$ centimetros. 
Examen microscópico: el estudio hisológico de los cortes muestra trompa uterina, apéndice y tejido adiposo muy probablementé epiplón; el conjunto presenta un proceso inflamatorio agudo caracterizado por edema, hemorra gia. congestión de los vasos sanguineos y por abundante infiltración leucocitaria polinuclear.

Hay en la muestra que parece co. responder a eplipón frecuentej granulomas del tipo por cuerpos extranion. El citoplasma de las célulaz gigantes xprisiona cristales de colesterol.

Diagnóstlco: Salpingitis y apendicitis aguda. Granulomas por cuerpos exraños.

(Fdo.), Méndez. Mayo 26,53.

\section{COMENTARIOS}

El estado febril de la paciente, apa. ecido unos dias antes del parto se exblica no tanto a fniección urinaria presencia de pus y bacterias en la rina), sino a la inyección infectada on la región glútea. La cesárea está ustificada no sólo por la incersión baa de la placenta y la procidencia del ordón. sino también por el eclampsisno y por las condiciones poco favoables del cuello para una dilatación rtificial. Ia laparotomía de precisión in el post-operatorio es una conducta auy recomendable no sólo en los esados peritoneales trancos, sino en los oco marcados, como el de nuestra aciente, tanto más si el diagnóstico s dudoso. Tomada esta medida con as debidas precauciones, generalmen ya coronada de éxito.
El cuerpo extraño causante de di. chos granulomas, bien puede ser el talco de los guantes o con más proba. bilidad la penicilina aplicada intrape ritonealmente con un fin profiláctico en la cesárea, en especial si esa ponicilina era de asorción lenta. (Preguntado despues el personal que atiende la sala de cirugia, no respondió con precisión sobre la clase de penicilina aplicada a este caso).

Es posible que dicho cuerpo extraño actuó como agente, si no casuad, sí agravante de la inflamación anexaapendicular.

De esto se desprende la necesidad de tener en cuenta en la operación cesárea la acción de los cuerpos extraños y sus complicaciones y de dejar en el peritoneo si es el caso, soluciones de penicilina sódica o potásica y no las de absorción lenta tipo procainica.

\section{RESUMEN}

19 Se presenta el caso de una multípara III, pre-eclámptica a quien se le practica una cesárea por placenta in. ferior y procidencia del cordón.

$2^{\circ}$ En el post-operatorio ofrece un estado peritoneal agudo aeterminado por granulomas por cuerpo extraño ligados a intlamación anexo-apendcular.

$3^{P}$ Estos hechos son demostrados lanto en la laparotomía de precisión como por el examen anatomo-patolo gico.

$4^{8}$ Se hacen algunos comentarios sobre la acción de cuerpos extraños (talco, penicilina procainica), intraperitonecies $y$ gus posibles complicacio. nes. 